\title{
Technology Integration Models and Frameworks in Teaching and Training
}

\author{
Jiwak Raj Bajracharya, PhD \\ Academic Dean, \\ GATE College, Mandikhatar, Kathmandu,Nepal \\ Email for Correspondence: jiwakraj@gate.edu.np
}

\begin{abstract}
The purpose of this study is to review the existing models and frameworks which has been implemented for technology integration during teaching and training. As discussed in the numerous literature Technological Pedagogical and Content Knowledge (TPACK), Substitution, Augmentation, Modification, Redefinition (SMAR), TPACK-based ID models such as TPACK-Comprehension, Observation of instruction, Practice of instruction, and Reflection on TPACK (TPACK-COPR) model, Introduce-TPACK, Demonstrate, Develop, Implement, Revise - a TPACK-based lesson, and Reflect on a TPACK-based lesson (TPACK-IDDIRR1) model, and TPACK-IDDIRR2 model have been applied by today's instructors and trainers to achieve the specific goal for effective teaching and training. This paper intends to highlight the key features of the above-mentioned models and frameworks with few hurdles as found in the empirical-based studies. It also discusses how those hurdles could be mitigated by addressing the extraneous cognitive load of instructors as well as trainers to carry out technology integration with future recommendations for the research. It was found that specific frameworks and models are limited to the macro-level concept but today's instructors, as well as trainers, are required to have adequate instructional guidance in chronological steps so that they could implement those models and frameworks in their teaching and training for productive outcomes.
\end{abstract}

Keywords: Cognitive Load, Extraneous, Framework, Technology Integration, TPACK

\section{Technology Integration}

Technology integration is very important in the twenty-first century learning society. Various components such as access to the technological resources, training for enhancing instructors' technical competencies, and favorable governmental plans and policies have been practiced to bring about technology integration. However, studies by numerous researchers revealed that these components are still not sufficient because technology-equipped classrooms and instructors' technical competencies alone do not guarantee in practicing successful technology integration (Kim, Kim, Lee, Spector, \& DeMeester, 2013; Polly, Mims, Shepherd, \& Inan, 2010). Meanwhile, studies done by Brickner (1995) and Vataartiran and Karadeniz (2015) made a case for the importance of instructors' personal beliefs in technology integration because it was related to their 
attitude towards technology integration. Other studies such as Bauer and Kenton (2005), Ertmer (2005) and Tsai and Chai (2012) revealed that instructors' competencies for creating technology-integrated lesson plans are of great importance because they are not able to carry out technology integration in the classroom, even with the presence of enough technological resources and having a positive attitude toward it. These studies highlighted the importance of instructors' competencies in designing and developing technology-integrated lesson plans because instructors are autonomous agents with the power to make decisions in their instruction.

A study done by Darnawati, Jamiludin, Mursidin, and Yuniar (2016) in Indonesia revealed that instructors were still incompetent in employing Instructional Design (ID) model such as ASSURE in creating a technology-integrated lesson plan for the classroom instruction because they lacked knowledge about the six-steps of the ASSURE model and were also very anxious about using technology in the classroom. This emphasizes that instructors from developing countries like Indonesia lack the required competencies to utilize the ID model itself for technology integration. Further, Mustafina (2016) argued that in the context of developing countries, there are gaps between instructors' existing level of competencies compared with the required level needed to employ ID models in practice. Therefore, even if, ID models were offered in the context of developing countries, there are still some limitations such as (i) the need of expert guidance to utilize the various steps of ID models, (ii) the lack of instructors' awareness about ID models, and (iii) the increased time and financial burden to the educational institutions. Typically, general ID models help instructors to integrate technology into teaching but they still demand some level of instructors' competencies about the models themselves, which could hinder the instructors from using such models especially in the context of developing countries.

COVID-19 further highlights an extreme need of technology integration not only in the general education but also for training programs including vocational education. Numerous researchers and practitioners already argued that technology integration is crucial for an effective teaching and training in 2Ts (Bajracharya, 2014; Bajracharya, 2016; Hunter 2015; Jang \& Tsai, 2012). So, today's instructors need to be aware about available technology models and framework including its advantages and hurdles before implementing in the practice.

\section{SAMR Model}

SAMR is a model developed to assist in integrating technology for classroom instruction. As defined by Hunter (2015, p.49), it "focused on explaining how instructors can consider technology integration in classroom teaching". SAMR is an acronym that stands for the four steps in the model developed by Puentedura (2006). Figure 1 illustrates the SAMR model in which the initial letter $S$ that stands for Substitution, which means that technology acts as a direct tool without functional changes. At this step, new technology could be utilized instead of the old ones. The second letter A stands for Augmentation, where technology acts as a direct tool for functional improvement. Third, M refers to Modification, where technology allows for the redesigning of the task for significant enhancement of instruction. Finally, R stands for Redefinition, where technology allows for creativity in creating new functions. Among the four steps of this model, the initial two steps (S and A) are considered as enhancement and the final two $(M$ and $R$ ) as transformation. The SAMR model supports and enables instructors to design and develop a lesson plan by infusing new technological tools. The major goal of the model is to enhance the learners' learning achievements. 


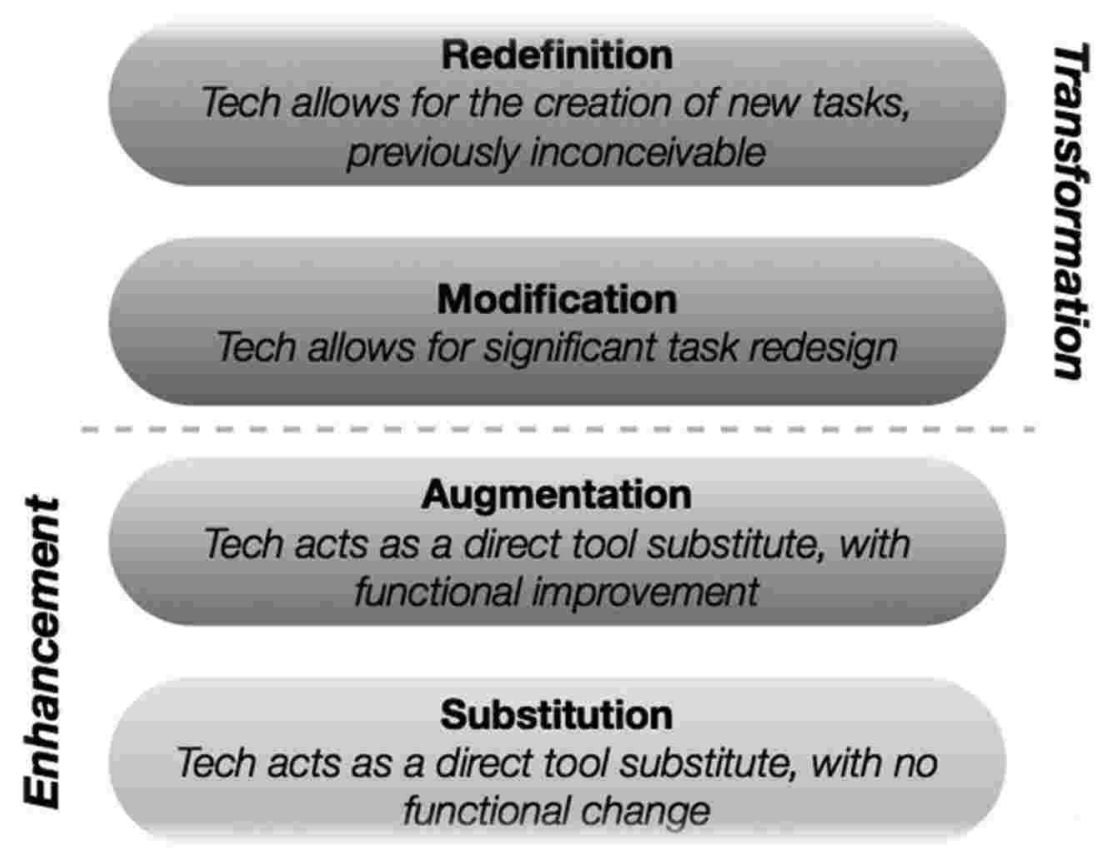

Figure: 1 SAMR Model

Source: Hunter, 2015, p.49

As highlighted by Melissa and Heather (2013), smartphones for educational applications and relevant educational websites assist to maximize the learning potential of elementary school learners by employing the four steps of the SAMR model to enhance the teaching and learning experiences of learners. In this study, learners were asked to use the educational application named Quicklyst for taking notes instead of using paper and a pencil. Further, learners were allowed to use smartphones in the classroom for note taking and were also permitted to share among the other learners for the enhancement of collaborative learning. Even more, learners were asked to create new ideas based on the classroom instruction that they had received in the class such as the creation of animation and so on. This is how the authors integrated new technologies in accordance with the four steps of the SAMR model. This revealed that the advancement of the technological tools enhances the learning experiences. However, the study still contains numerous issues such as the technical competencies of instructors and learners, and the effectiveness of new technologies compared with an old technology. However, Jude, Kajura, and Birevu (2014) conducted a study in Uganda for carrying out technology integration in the classroom instruction. Based on the instructors' experiences regarding the use of the SMAR model, they found that four steps were very complicated to follow, even if, their pedagogical strategies resulted in improvements. Replacement of old technologies with new ones was not straightforward and needed detailed guidance to utilize those steps for carrying out technology integration during the classroom instruction. Thus, as researched by Linderoth (2013), even if, SAMR has been practiced for technology integration in the classroom instruction, it still lacks an established theoretical background, which needs to be investigated further. Even more, apart from the perspective of theory, the four steps of SAMR could create technology integration in the classroom instruction. However, the use of detailed guidance 
for instructors to utilize those four steps has not been investigated yet. Thus, instructors could experience difficulties in technology integration as discussed above.

\section{TPACK Framework}

A Technological Pedagogical and Content Knowledge (TPACK) framework builds on Shulman's (1986) concept of Pedagogical and Content Knowledge (PCK) to explain how instructors' Technological Knowledge and PCK interact to carry out technology integration in the classroom instruction. This framework provides a visualized perspective of the three major pieces of knowledge required by instructors for technology integration.

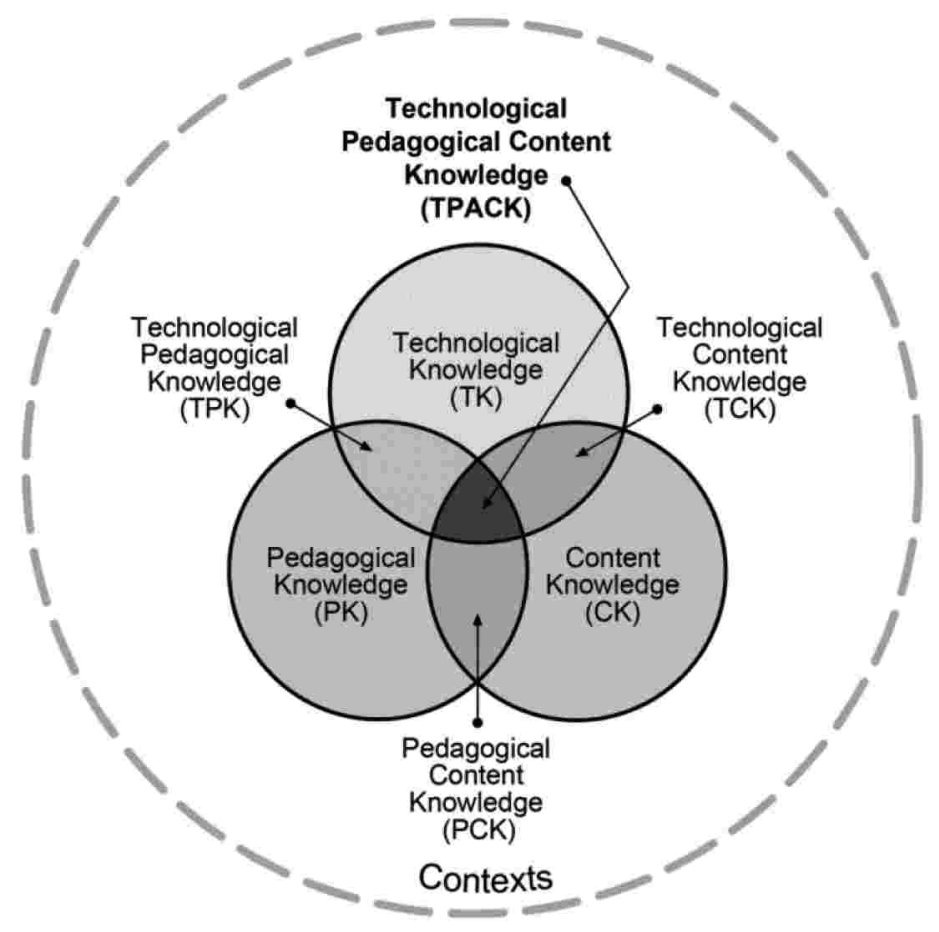

Figure: 2 TPACK Framework

Source: Koehler, and Mishra, 2008, p.16

TPACK is a combination of three knowledge required by instructors for carrying out technology integration and was based on content, pedagogy, and technology (Haris, Mishra, \& Koehler, 2009; Jang \& Tsai, 2012; Mishra \& Koehler, 2006). It provides the three specific elements that instructors could consider in technology integration during 2Ts: content (knowing the subject matter), pedagogy (understanding how to teach), and technology (knowing technological tools and its applications). Figure 2 represents a TPACK framework that comprises seven different forms of knowledge established after the intersection of three specific kinds of knowledge as Content Knowledge, Pedagogical Knowledge, and Technological Knowledge.

Content knowledge. Content Knowledge (CK) is the instructors' knowledge about the course matter including curricular knowledge (Mishra \& Koehler, 2006). It includes the instructors' concepts, theories, ideas, and evidence (Shulman, 1986). It is one of the three main specific pieces of instructors' 
knowledge regarding discipline and relevant contents. For instance, knowledgeable instructors of content could broaden a classroom instruction into real-life situations to help the learners connect with the material.

Pedagogical knowledge. Pedagogical Knowledge (PK) is the instructors' knowledge about instructional strategies that includes intensive competencies about the practices (Koehler \& Mishra, 2008). Pedagogy is the science of teaching and consists of various techniques, and instructional strategies utilized during classroom instruction to enables learners to learn. It is also one of the three main specific areas of knowledge. Further, Koehler and Mishra (2008) explained that instructors with PK could utilize relevant instructional strategies during classroom instruction to further enhance the learners' learning regarding content. Mishne (2012) argued that PK is also part of the professional body of knowledge that assists in understanding the process of delivering instruction.

Technological knowledge. Technological Knowledge (TK) is the instructors' knowledge of technological tools, programs, and its applications. Since technology is always changing and updating, Mishra and Koehler (2006) found that instructors could experience difficulties to master their TK because of rapid transformation. It is one of the main areas of knowledge about TPACK that was added into Shulman's PCK, which represents "individual tools or techniques, and all tools and techniques and knowledge" (Mishra \& Koehler, 2006, p.5). It refers to the instructors' knowledge about relevant and recent technologies such as internet, videos, smartphones, applications, Bluetooth, social media, online learning tools, and many more. It also includes computer skills including word processing, Excel, PowerPoint, etc. If the instructors have sound understanding about TK, they can have better options for technology integration. Instructors could also take advantage of the available technologies to enhance the learning and prepare the learners for the twenty-first century. Further, the instructors' attitude towards technology makes a significant impact on utilizing technology during classroom instruction.

Pedagogical content knowledge. PCK is the most crucial knowledge that is associated with the instructors' instructional strategies to deliver the required content. As reported by Koehler and Mishra (2008), quality teaching is about the transformation of content with the adaptation of relevant pedagogical strategies regarding the material.

Technological content knowledge. Technological Content Knowledge (TCK) is a combination of TK and CK. As explained by Mishra and Koehler (2006), TCK is the understanding of how technology and content influence and constrain each other. The key concept of TCK is to represent content matters effectively with the adoption of appropriate technological applications. Thus, instructors with TK could deliver the required content. For instance, the implementation of educational software named Geometer's Sketchpad to provide a better conceptual understanding of geometry is an example of using TCK.

Technological pedagogical knowledge. Technological Pedagogical Knowledge (TPK) is about how teaching and learning changes when technologies are used (Mishra \& Koehler, 2006). It is important to know the strengths, constraints, and affordances of the technologies before designing and developing a technology-integrated lesson plan. Instructors could examine various pedagogical strategies before considering any technologies for classroom instruction to achieve the learners' learning experiences such as engaging learners in the classroom and enhancing their learning outcomes.

A research conducted by Dalal, Archambault, and Shelton (2017) utilized a TPACK framework among instructors from developing countries. To investigate the instructors' competencies regarding TPACK and to create technology-integrated lesson plans, the authors employed a mixed-method research design including surveys and interviews. After the semester- 
long course, the findings of the study revealed that even if instructors' competencies regarding TPACK had improved they still found difficulties to create a technology-integrated lesson plan for classroom instruction. Further, interview data revealed that even if instructors were competent in content, pedagogy, and technology, they were not able to create a technology-integrated lesson plan after being trained to use a TPACK framework. Thus, the authors concluded that having a high level of the instructors' knowledge of TPACK could not guarantee the enhancement of their competencies for carrying out technology integration. This was because TPACK lacks the structure to create a technology-integrated lesson plan. Further, Padmavathi (2016) argued that a TPACK framework requires detailed information to create a technology-integrated lesson plan. Thus, based on the evidence discussed above, a TPACK framework is not sufficient for creating a technologyintegrated lesson plan to integrate content, pedagogy, and technology simultaneously. But still numerous studies have been carried out based on TPACK.

As discussed above, the SAMR model and the TPACK framework were developed specifically for technology integration. Both the SAMR model and the TPACK framework specify the key procedures and key knowledge required by the instructors for technology integration. However, they also consist of few drawbacks such as (i) the SAMR model is very difficult to implement in practice because it lacks detailed guideline for instructors, and (ii) the TPACK framework also lacks a detailed structure for creating a lesson plan by integrating content, pedagogy, and technology simultaneously. Thus to address such hurdles TPACK-based ID models has been developed which is discussed below.

\section{TPACK-based Instructional Design Models}

Despite having models including Instructional design models, SAMR, a TPACK framework has been increasingly utilized for technology integration in the classroom instruction. As argued by Kopcha, Ottenbreit-Leftwich, Jung, and Baser (2014), a TPACK framework is becoming popular because it provides three specific elements, which need to be considered by instructors for carrying out technology integration (Bajracharya, 2019b). To provide a systematic ID model based on a TPACK-framework, three TPACK-based ID models have also been developed. The key focus of those models is to enhance the TPACK level of instructors. The three TPACK-based ID models have been developed to train the instructors to develop technology-integrated lessons.

(1) TPACK-COPR model. Jang and Chen (2010) developed a TPACK-based ID model for enhancing TPACK competencies of instructors in the science curriculum. The authors had developed a TPACK-COPR model based on PCK, a TPACK framework, and peer coaching as a theoretical background. This model includes four major phases such as TPACK Comprehension (C), Observation of instruction (O), Practice of instruction (P), and Reflection on TPACK (R). Jang and Chen (2010) implemented a TPACK-COPR model in a science course for 18 weeks, which was scheduled for two hours every day. The key purpose of this model was to enhance the competency level of TPACK among instructors. During the intervention period, instructors were assigned to understand a TPACK framework, which improved the technical competencies of instructors and its application for the initial four weeks. Then, instructors observed a TPACK based classroom instruction provided by the experts for two weeks. Further, instructors practiced a TPACK framework for nine weeks| by designing and developing a TPACK-based lesson plan. In this phase, instructors learned to make a lesson plan for classroom teaching. Finally, the reflection was carried out for three weeks to receive feedback from the experts. The findings revealed that the four phases of a TPACK-COPR model offered possible opportunities for instructors for designing and developing a lesson plan in the science course. However, based on the reflection notes, 
instructors also had experienced difficulties in integrating content, pedagogy, and technology in creating a technology-integrated lesson plan. This implies that instructors with a high level of TPACK do not necessarily have sufficient competencies to design and develop technology integrated lesson plans on their own.

(2) TPACK-IDDIRR1 model. TPACK-IDDIRR1 is a procedural ID model developed by Lee and Kim (2014a), and stands for Introduce - TPACK, Demonstrate, Develop, Implement, Revise - a TPACK - based lesson, and Reflect on a TPACK based lesson. The purpose of this model is to develop an ID model for instructors to enhance their TPACK competencies in multidisciplinary courses for carrying out technology integration. Among the six phases, the initial two were carried out by the instructors to provide the concept of a TPACK framework and demonstrate a TPACK based lesson for instructors. After that, the remaining four phases were performed by trainees. Except for the developmental phase, the implement, revise, and reflection stages were carried out multiple times to enhance the competencies of instructors regarding a TPACK framework. The model was based on the TPACK, learning by design approach, and ID models for technology integration as a theoretical foundation.

(3) TPACK-IDDIRR2 model. TPACK-IDDIRR2 is an elaborated version of TPACK-IDDIRR1. This model is also a procedural ID model developed by Lee and Kim (2014b), which was divided into three steps. Step 1 focuses on how to understand a TPACK framework including an initial phase as Introduction of TPACK by instructors that provides TPACK teaching examples, in which trainees explore, discuss, and create TPACK examples and its related domains. Secondly, step 2 involves engaging in TPACK activities, and consists of three major phases: Develop, Reflect on, and Revise and Gain feedback. In this step, instructors are engaged in a TPACK-based lesson plan with three different types of technologies for three times. Finally, step 3 is to practice TPACK that included four major phases consisting of Develop, Gain feedback, Implement, and Reflect on and Revise. In both of the steps, a learning TPACK by design approach is practiced similar to the TPACK-IDDIRR1 model.

Three TPACK-based ID models are part of a crucial set of knowledge that instructors have to know for enhancing their competencies regarding a TPACK framework. The aforementioned three models provide various steps and phases along with their functions, but still lack detailed guidance to utilize those steps and phases, which could be considered as a limitation. Further, structural procedures to design and develop a technology-based lesson plan were not offered to integrate content, pedagogy, and technology simultaneously.

As highlighted by Bajracharya (2019a) since those models were constructed in the developed countries, it can be assumed that the first-order barrier (technological resources and trainings) might not exist in their contexts. Also, based on the various phases of those models, instructors also experienced difficulties to follow the processes of TPACK-based ID models because of the lack of enough guidance.

The primary goal of TPACK-based ID models is to enhance TPACK competencies of instructors for carrying out technology integration in the classroom instruction but these models possess limitations in terms of (i) how instructors utilize a TPACK-based ID model (ii) instructors' competencies for creating technology-integrated lesson plans and (iii) changes in the learning experiences of instructors after using those models. However, the key component of the ID model is to help instructors, which was not investigated during the implementation of TPACKbased ID models among trainees.

Therefore, to address these gaps found in the literature, a new ID model for instructors needs to be considered for creating a technology-integrated 
lesson plan to carry out technology integration in the classroom instruction. A TPACK-integrated ID model needs to be developed and validated in future studies by considering the three elements of TPACK and a generic ID model.

\section{References}

Bajracharya, J. R. (2014). Entanglement of higher education and strength of open and distance learning in Nepal. American Journal of Educational Research, 2(11), 1091-1093.

Bajracharya, J. R. (2016). Strength of traditional and social media in education: A review of the literature. Journal of Research and Method in Education, 6(6), 13-21.

Bajracharya, J. R. (2019a). TPACK-integrated worked examples for technology integration. Journal of Training and Development, 4, 46-63. https://doi.org/10.3126/jtd.v4i0.26837

Bajracharya, J. R. (2019b). Instructional Design and Models: ASSURE and Kemp. Journal of Education and Research, 9(2), 1-9.

Bauer, J., \& Kenton, J. (2005). Toward technology integration in the schools: Why it isn't happening. Journal of Technology and Teacher Education, 13(4), 519-546.

Brickner, D. L. (1995). The effects of first and second order barriers to change on the degree and nature of computer usage of mathematics teachers: A case study. Unpublished doctoral dissertation, Purdue University, West Lafayette.

Dalal, M., Archambault, L., \& Shelton, C. (2017). Professional development for international teachers: examining TPACK and technology integration decision making. Journal of Research on Technology in Education, 46(3-4), 1-17.

Ertmer, P. A. (2005). Teacher pedagogical beliefs: The final frontier in our quest for technology integration? Educational Technology Research। and Development, 53(4), 25-39.

Harris, J., Mishra, P., \& Koehler, M. (2009). Teachers' technological pedagogical content knowledge and learning activity types: Curriculum-based technology integration reframed. Journal of Research on Technology in Education, 41(4), 393-416.

Hunter, J. (2015). Technology integration and high possibility classrooms. New York, NY: Routledge.

Jang, S.J., \& Chen, K.C. (2010). From PCK to TPACK: Developing a transformative model for pre-service science teachers. Journal of Science Education and Technology, 19(6), 553-564.

Jang, S.J., \& Tsai, M.F. (2012). Exploring the TPACK of Taiwanese elementary mathematics and science teachers with respect of interactive whiteboards. Computers and Education, 59(2), 327-338

Jude, L. T., Kajura, M. A., \& Birevu, M. P. (2014). Adoption of the SAMR model to asses ICT pedagogical adoption: A case of Makerere University. International Journal of e-Education, e-Business, e-Management and e-Learning, 4(2), 106-115.

Kim, C., Kim, M. K., Lee, C., Spector, J. M., \& DeMeester, K. (2013). Teacher beliefs and technology integration. Teaching and Teacher Education, 29, 76-85.

Koehler, M. J., \& Mishra, P. (2008). Introducing TPCK. In M.J. Koehler \& P. Mishra (Eds.), Handbook of technological pedagogical content knowledge for educators (pp 3-29). New York, NY: Routledge.

Kopcha, T. J., Ottenbreit-Leftwich, A., Jung, J., \& Baser, D. (2014). Examining the TPACK framework through the convergent and 
discriminant validity of two measures. Computers and Education, 78, 87-96.

Lee, C. J., \& Kim, C. (2014a). An implementation study of a TPACK-based instructional design model in a technology integration course. Educational Technology Research and Development, 62(4), 437-460.

Lee, C. J., \& Kim, C. (2014b). The second prototype of the development of a technological pedagogical content knowledge based instructional design model: an implementation study in a technology integration course. Contemporary Issues in Technology and Teacher Education, 14(3), 297 326.

Linderoth, J. (2013). Open letter to Dr. Ruben Puentedura [Blog post]. Retrieved on December 15, 2017, from http://spelvetenskap. blogspot. com/2013/10/openletter-to-dr-ruben-puentedura. html.

Melissa, J.I., \& Heather, M, H. (2013). Redefining technology in libraries and schools: AASL best apps, best websites, and the SAMR model. Teacher Librarian, 42(2), 16-19.

Mishne, J. (2012). An investigation of the relationships between technology use and teachers' self-efficacy, knowledge and experience. Unpublished doctoral dissertation, Pepperdine University, CA.

Mishra, P., \& Koehler, M. (2006). Technological pedagogical content knowledge: A framework for teacher knowledge. The Teachers College Record, 108(6), 1017-1054.

Mustafina, A. (2016). Teachers' attitudes toward technology integration in a Kazakhstani secondary school. International Journal of Research in Education and Science, 2(2), 322 332.
Padmavathi, M. (2016). Preparing teachers for technology based teaching learning using TPACK. I-Manager's Journal on School Educational Technology, 12(3), 1-9.

Puentedura, R. R. (2006). The SAMR model: Transformation, technology, and education. Retrieved on November 17, 2017, from http:// hippasus.com/resources/tte

Polly, D., Mims, C., Shepherd, C. E., \& Inan, F. (2010). Evidence of impact: Transforming teacher education with preparing tomorrow's teachers to teach with technology (PT3) grants. Teaching and Teacher Education, 26(4), 863-870.

Shulman, L.S. (1986). Those who understand: Knowledge growth in teaching. Educational Researcher, 15(2), 4-14.

Tsai, C. C., \& Chai, C. S. (2012). The" third"-order barrier for technology-integration instruction: Implications for teacher education. Australasian Journal of Educational Technology, 28(6), 1057 1060.

Vatanartiran, S., \& Karadeniz, S. (2015). A needs analysis for technology integration plan: Challenges and needs of teachers. Contemporary Educational Technology, 6(3), 206-220. 